\title{
Entrevista: Lélia Gonzalez - Intérprete do Brasil. Por seu filho Rubens Rufino
}

\author{
Interview: Lélia Gonzalez - Interpreter \\ of Brazil. By Her Son Rubens Rufino
}

Entrevista realizada online com Rubens Rufino (Brasília), em 2 de fevereiro de 2021, por Amanda Motta Castro* (Porto Alegre-RS) e Raylene Barbosa Moreira** (Rio Grande-RS).

Nascido no início da década de 1960, Rubens Rufino era caçula de Dora, que já tinha três outros filhos. Devido às dificuldades, Dora pensou em desistir da gravidez, mas Lélia incentivou sua irmã a ter o filho, pois era independente financeiramente, portanto, poderia auxiliá-la. Desta forma, Rubens tornou-se o filho único de Lélia Gonzalez (19351994). Formado em Economia, Rubens foi o responsável por datilografar a obra da mãe: manifestos, cartas, artigos, palestras e panfletos. Atualmente, é o idealizador do Projeto "Lélia Gonzalez Vive", que busca preservar e manter vivo o legado de Lélia.
Born in the early 1960s, Rubens Rufino was the youngest child of Dora, who already had three other children. Due to the difficulties, Dora thought of giving up the pregnancy, but Lélia encouraged her sister to have the child, because she was financially independent, therefore, she could help her. Thus, Rubens became Lélia Gonzalez's (1935-1994) only child. An Economics graduate, Rubens was responsible for typing his mother's work: manifestos, letters, articles, lectures, and pamphlets. Currently, he is the idealizer of the "Lélia Gonzalez Vive” Project (Lélia Gonzalez Lives), which seeks to preserve and keep alive Lélia's legacy.

Amanda Castro (A. C.): Por insistência das minhas estudantes, que me pediam: "Vamos fazer um grupo de pesquisa?", eu sempre ficava relutante. "Para que mais um grupo?”. Mas aí, eu fiz uma pesquisa no CNPq e vi que nós só tínhamos um grupo Lélia Gonzalez, que é um grupo da UnB. Aí eu disse: "não, eu acho que é muito feio o Brasil ter só um grupo.". E então, criamos o "Grupo de Pesquisa Interdisciplinar Lélia Gonzalez". Nós temos mais grupos Angela Davis do que grupos Lélia Gonzalez, portanto, começa-

\footnotetext{
* Universidade Federal do Rio Grande (FURG), Porto Alegre, RS, Brasil. motta.amanda@terra. com.br <https://orcid.org/0000-0003-0471-1240>

** Universidade Federal do Rio Grande (FURG), Porto Alegre, RS, Brasil. raylenemoreira95@gmail. com <https://orcid.org/0000-0001-9641-634X>
} 
mos a trabalhar com o grupo. Eu te procuro há um tempo, já, pois eu sabia que a Lélia tinha um filho e que tu estavas por aí em algum lugar, então, fazia tempo que eu estava tentando te encontrar. A primeira pergunta é esta: Rubens, como é ser filho da Lélia? Por onde tu andas e o que tu fazes sendo filho dessa mulher maravilhosa que foi Lélia Gonzalez?

Rubens Rufino (R. R.): Bom, é... Eu me chamo Rubens, tenho 59 anos. Sou pai da Melina e do Marcelo, avô da Dorinha e filho de Lélia. Sou graduado em Economia, economista. Estou fazendo agora uma segunda graduação. E, atualmente, eu moro em Brasília. Nós nos mudamos para Brasília em 1998. Aí, em 2014, eu me separei e fiquei um tempo no Rio (RJ). Voltei para Brasília, e aqui estou prestes a dar entrada em minha aposentadoria, por conta dessa coisa de pandemia aí; de você ficar travado para poder fazer as coisas, se locomover, ir para alguns lugares... E, atualmente, a gente - que somos eu, meu filho Marcelo, minha filha Melina e a minha prima-irmã Eliane, a Lili - está empenhado em fazer a promoção, em difundir o pensamento da Lélia Gonzalez. Com isso, até o final desse mês, a gente vai ter o Instituto Memorial Lélia Gonzalez. Temos uma missão enorme, né? Difundir e manter o legado dela, falar da Lélia de Almeida, a Lélia da família e a Lélia Gonzalez, a ativista, que a grande maioria das pessoas conhece, a intelectual, a cientista social. Mas, com a Lélia de Almeida, foram poucas as pessoas que tiveram a oportunidade de conviver intimamente, né? Cito o Januário Garcia, que eu conheci, também mineiro, de Belo Horizonte, e tem a Dulce Pereira, que era uma amiga, estava lá em casa sempre. Outros, que não estão mais conosco, como a Luíza Bairros, além de outras pessoas que frequentavam nossa casa. Quer dizer, independentemente da relação de ativismo da minha mãe, essas pessoas que frequentavam a nossa casa tinham uma relação muito mais estreita e participavam de várias situações de intimidade, de que muitos não tiveram a oportunidade de participar, devido às restrições que ela fazia de convidar alguém para ir à casa dela. Então, hoje, a minha grande missão é desenvolver o Instituto Memorial Lélia Gonzalez, junto com meus filhos e minha prima-irmã. Meu foco, hoje, por enquanto, é esse.

\section{A. C.: Eu assisti a uma live com os teus filhos. Eu vi você fazendo comentários e foi a partir dessa live que eu te achei. Eu não sabia que esse instituto estava nas mãos da família.}

R. R.: Não, não. O Instituto Lélia Gonzalez, que é voltado para os estudos de gênero e raça, é em São Paulo. Esse é um instituto que tem um viés diferen- 
te do nosso. O instituto que a gente está fundando é um memorial, que vai falar exclusivamente sobre o pensamento dela e o seu legado. Esse outro, embora tenha levado o seu nome, tem um viés diferente, é uma homenagem que as pessoas lhe fizeram. Bem legal! Trabalha com excluídos, com mulheres, principalmente com mulheres negras. Esse de que a gente está falando, Amanda, é o da Lélia, mesmo. Queremos pegar o pensamento dela e difundir, promover em universidades, enfim. Tudo em que a gente possa contribuir. Porque, eu ouço muita gente falando... Como você disse, a própria Angela Davis, quando esteve no Brasil, citou Lélia Gonzalez. Angela afirmou que, enquanto para nós, brasileiros, ela própria é uma referência importante do movimento negro, a figura que ela tem como referência é Lélia Gonzalez. Então, sabe, é uma coisa mais ou menos por aí. A gente está querendo reforçar isso.

\section{A. C.: Perfeito! Que lindo! A gente fica super à disposição. Eu trouxe três li-} vros para a entrevista: Lélia Gonzalez, por Flávia Rios e Alex Ratts, Primavera para as rosas negras, da UCPA, e o último da Flávia Rios e da Márcia Lima, que se chama Por um feminismo afro-latino-americano.

R. R.: Na verdade, no da UCPA, que é da União dos Coletivos Panafricanistas, eles fizeram um trabalho diferente, Amanda. Eles conseguiram fazer uma coletânea de textos dela e o objetivo desse projeto deles era... Era não, é, difundir o pensamento de Lélia Gonzalez no movimento negro, para jovens que não tiveram a oportunidade de conhecê-lo. Já esse, que a Flávia e a Márcia fizeram e organizaram, tem mais textos, mais pensamentos dela do que o outro, porque elas conseguiram textos que estavam em inglês, textos que estavam em francês, textos que estavam em espanhol, e traduziram para o português. Então, eu posso dizer, assim, eu acredito que esse [refere-se ao livro Por um feminismo afro-latino-americano] deva ter uns $98 \%$ do que ela produziu. Mas, ao longo do tempo, pode ser que surja mais alguma coisa mexendo daqui, mexendo dali. Aí, já tem um diferente. Esse da Companhia das Letras tem como objetivo difundir, mesmo, o pensamento dela no Brasil. Já tem uma proposta que está sendo formalizada, que é a tradução para o espanhol, para o francês e também para o inglês. O nosso objetivo é difundir isso pelos cantos em que ela andou: pela Europa, pelos Estados Unidos, pela América do Norte, ela andou pela África. Quão legal será que a gente consiga ter a oportunidade de traduzir e ter mais gente que possa conhecer o que ela pensava, né? Sem falsa modéstia, o que ela pensava há quarenta anos é atual, contemporâneo, o que, para mim, é o mais incrível. 


\section{A. C.: A luta do que ela escreve, o que ela sistematiza teoricamente, é ainda muito a conquistar, né?}

R. R.: Sim, e uma coisa muito interessante nisso tudo, Amanda, é que me perguntam: "Ah, você se sente orgulhoso por ser filho de Lélia?". Eu, como filho, fico muito orgulhoso e sei que nossos familiares, os Almeida, têm um grande orgulho do que ela fez, do que ela produziu. Mas esse meu orgulho, Amanda, ele transcende a relação mãe e filho, porque o grande orgulho que eu tenho, é que ela foi uma pessoa que lutou pela causa de um povo, que abriu mão de várias coisas da vida pessoal dela para poder levantar essa bandeira do racismo no Brasil, a luta por uma sociedade mais igualitária, mais democrática. Então, esse grande orgulho meu... Eu não tenho procuração, mas eu posso falar por eles [risos]... meus filhos, minha prima-irmã, assim, eu acho que eles assinam embaixo do que eu estou falando para vocês.

\section{A. C.: E quem ficou? Quem mais? Tem algum irmão de Lélia que ainda está vivo? Porque ela morreu muito jovem.}

R. R.: Não, morreram todos. Na família Almeida, todos faleceram jovens, não tem mais nenhum. A última, na família Almeida, minha tia Lygia, morreu em 1998. E a minha tia, Judith, esposa de um tio meu, faleceu no ano passado. Então, do que a gente chama da primeira geração, não tem mais ninguém. Só temos a segunda geração, que somos nós. Aí, tem a terceira, a quarta, a quinta... Imagina, uma família em que treze filhos, como se falava na época, "vingaram" - e uma família preta que não tem nem muitos filhos, tem quatro, cinco, seis filhos. Então, o negócio é que a gente conseguir unir o pessoal. A gente tem um encontrão. Agora não, por conta da pandemia, né? Mas assim, no Rio, a gente marcava num domingo, num sábado, e reunia primos e primas, boa parte da família, fazia um churrasco, fazia uma feijoada, sabe? Para rever, trocar. E a coisa mais interessante é que, nas famílias pobres e pretas, principalmente, a história se dá pela oralidade, né? Então, nós, da família, ficamos sabendo o que aconteceu com as pessoas - inclusive, sabendo de histórias do tempo em que não tínhamos nem nascido, contadas pela minha avó, pelas minhas tias. Então, é isso aí, é muito emocionante e legal! 
A. C.: E, uma pessoa que me chama atenção na história da Lélia é o irmão, o Jayme, que vai para o Rio e leva a família toda, né? Quando ele assina o contrato com o Flamengo. O filho do Jayme também trabalhou no Flamengo. Ele é vivo?

R. R.: Claro. Deixa eu te explicar mais ou menos o que aconteceu. O meu tio jogava no Atlético Mineiro, porque o meu avô era, acho, chefe da estação. Ele trabalhava na Rede Ferroviária da Estação S. A. Então, ele conheceu a minha avó em Vitória, aí teve filhos capixabas. Como ele teve filhos nos quatro estados do Sudeste, capixabas, paulistas, cariocas e mineiros, então, os mais novos, os quatro mais novos, nasceram em Minas, Belo Horizonte. E o tio Jayme é um dos mais velhos. O tio Jayme, no ano passado, completaria 100 anos. A diferença dele para minha mãe é de 15 anos, então, ele foi meio que o pai dela, porque vovô morreu cedo. Então, quando ele foi transferido para o Rio de Janeiro, a família veio junto, os irmãos, aquela coisa toda. Ele teve um papel de destaque no Flamengo. Eu tive pouco contato com o tio Jayme. Na casa da minha avó, me lembro de que as minhas tias e primas comentavam que, quando ele mandava um telegrama - na época do telegrama - dizendo que estava vindo ao Brasil, "a vovó botava todo mundo para arrumar a casa, dar uma faxina porque ia receber o filho”. E a relação dele com Lélia era uma relação meio que de pai para filha, até pela diferença de idade, né? E ele deu muita força para que ela ingressasse na Universidade, porque ela era diferente de todas as irmãs. Pela criação que elas tiveram, que a minha avó deu e que eu não vou entrar no mérito de discutir - mas é uma realidade própria das famílias negras, assim, de preparar para casar, para ser esposa. E ela teve força, o tio Jayme compactuou com ela e a ajudou nos estudos, bancava os seus estudos. Quer dizer, ela estudou em colégios públicos, mas tinha que comprar livros, tinha que se locomover, tinha que comprar uniformes. Os irmãos deram essa força para ela, e ela foi a única da família que se formou. O tio Jayme foi muito importante na vida dela, porque eles tinham essa relação de pai e filha, porque o vovô morreu antes dos anos 50, ela era adolescente ainda, entendeu? Aquela coisa dos irmãos mais velhos, né? Os outros tios, mesmo, eu nem tive a oportunidade de conhecer. O tio Braulio, o tio Alfredo e o tio Acacinho, que eram os mais velhos, eram casados e tal. Mas era aquela coisa: vovó era como uma galinha que bota os filhos embaixo da asa dela, entendeu? Mesmo os filhos casados tinham que se reunir para comer, uma coisa assim, bem legal! Então, essa relação com tio Jayme e com meu primo Jayminho, que faz parte do nosso grupo, da família Almeida... Jayminho seguiu carreira no futebol e teve sucesso. 95\% da minha família são flamenguistas. A última conquista de Jay- 
minho foi em 2013, na Copa do Brasil, no Flamengo, como técnico. Então, assim, a relação da família Almeida com o Flamengo é muito grande! Eu tenho um outro tio também, o tio Tião, que jogou. O tio Jayme é do primeiro tricampeonato, nos anos 40. O tio Tião jogou outro tricampeonato nos anos 50. Para você ver, a relação da família com o Flamengo é muito forte.

\section{A. C.: Claro. E foi um dos primeiros atletas negros a jogar o futebol profissio- nal, né?}

R. R.: Sim, como profissional.

A. C.: Nas entrevistas ela lembrava isso, né? Mas você me falou agora que as mulheres na geração de Lélia eram pensadas e formadas para casar e sair tendo filhos, e para ficar em casa. Lélia fez tudo ao contrário, né? Virou uma intelectual, uma mulher livre, e rodava o mundo, como você já disse. Ela era poliglota, falava vários idiomas, quatro idiomas. E tem uma questão na vida de Lélia que me chama muita atenção, nesse tempo em que a gente está debatendo o colorismo, que é o casamento dela com Luiz Carlos Gonzalez. Ela fala disso em algumas entrevistas com muita tranquilidade, uma tranquilidade que parece a de uma mulher analisada, mesmo. O que ela falava desse período, desse casamento dela? Ou ela não falava sobre isso?

R. R.: Falava. Deixe-me explicar uma coisa para vocês, para que possam entender: a Lélia tinha, dentre as irmãs, uma com quem ela tinha mais afinidade - eram grandes amigas, era a Dora. Nessa história toda de luta quando cresceu, ela acabou se afastando da família, então, as irmãs com quem ela tinha mais contato eram a Dora e a Eliza - que era a irmã mais velha de todas, foi a primeira filha dos meus avós -, além do Geraldo, que era o caçula, e veio logo depois dela. São esses com quem ela tinha mais convivência de família. A Dora era casada, tinha três filhos. Ela se separou, foi morar com a minha avó. Nessa história, a grande paixão da vida dela era o marido. Então, quando o marido ia lá visitar os filhos, na casa da minha avó, eles acabavam namorando. Num desses namoros, a Dora engravida, então, ela tinha três filhos, com diferença de dois anos entre eles, e aí veio o outro filho, que tem quatro anos de diferença, e que sou eu. Quando a Dora descobriu a gravidez, quando a barriga começou a crescer, você imagina? Foi no início dos anos 60 . Uma mulher preta, separada, que era chamada de "largada", ter um quarto filho e não estar mais casada com o marido, você imagina a barra que ela seguraria? E Lélia falou para ela assim: "não, Dora, onde comem três, comem quatro". Aí, as duas 
me contaram que, quando eu nasci (nasci no hospital que hoje é o Quinta D’or, que era uma maternidade pública), a Lélia foi fazer visita ao sobrinho e a Dora, simbolicamente, entregou o filho assim: "toma que o filho é seu". Aí, o que acontece, quando eu comecei a aprender a palavra "mãe", eu chamava Lélia e Dora de mãe, sem ninguém ter me ensinado. E a Lélia me bancou, me assumiu como filho e assumiu toda a minha criação - diferente dos outros, porque eu estudei em colégio particular, sou graduado, e você conta nos dedos, nessa família enorme de que eu te falei, quem é graduado. São pouquíssimos os que conseguiram uma graduação. Enfim, estudei inglês, estudei francês, aquela coisa toda. Ao longo do tempo, para vocês entenderem, aos 22, 23 anos, ela começou a fazer regressão, né? Eu sempre dividi a Lélia e a Dora. Ficava durante a semana na casa da Dora e, no final de semana, na casa da Lélia. Com mais ou menos 16 anos, eu me mudei definitivamente para a casa de Lélia, fui morar com ela. E aí, quando eu tinha 22 anos, ela começou a fazer regressão e ela aprendeu a fazer regressão, porque ela, uma sumidade, conseguia estudar tudo com profundidade. Ela não fazia em mim por conta de ser filho, né? Ela me contou isso muito emocionada: que, em todas as vidas passadas dela, eu fui filho dela. Então, eu sou o filho que biologicamente ela não teve, mas sou o filho que tinha que nascer para ela. Eu tenho o privilégio de ter duas mães. O Luiz Carlos, a quem eu chamava de pai - eu não tinha pai, né?... Eles eram separados, então, ele foi meu pai, pai Cal. E foi uma barra muito grande, você imagina, uma família espanhola, classe média. Enquanto ainda estavam namorando, era aquela coisa: "ah, tá, ele tá com uma pretinha, deve estar comendo a pretinha e tal”, né? Aquela coisa com que a família não se importava. Quando eles resolveram se casar, foi uma confusão, pois a família dele não aceitava de forma alguma. Isso foi uma grande barra para o pai Cal, foi muito difícil para ele. Chegou um momento, um momento de falta de lucidez, em que ele acabou tirando a vida. Foi uma porrada para Lélia, né? Minha mãe ficou arrasada por conta disso tudo. Ela manteve o sobrenome Gonzalez, porque ele foi um cara que mostrou para ela que ela era preta, negra, que ela tinha que lutar. Foi o cara que deu muita força nesse sentido, inclusive segurando a barra junto com ela, na coisa do racismo, do preconceito da família dele para com ela. Eu só soube desse episódio que ele tinha tirado a vida, quando eu tinha 18 anos. Me falavam assim: “ah, o pai Cal está no céu, viajou”. Aí, minha mãe chegou, me chamou numa conversa íntima e falou: "olha, o pai Cal, o Luiz Carlos, tirou a vida". Isso foi um choque para mim muito grande. Mas, na época, eu deveria ter uns 4, 5 anos, eu não ia entender isso de jeito nenhum. Já foi difícil entender a perda de uma pessoa, então, assim, você imagina uma 
coisa da forma trágica como foi? E é por isso que ela manteve o nome Gonzalez, e ele foi uma pessoa muito importante na vida dela, um grande homem que ela teve.

A. C.: Eu me emociono muito com essa história, Rubens, porque a gente tem aí o debate da "palmitagem" e, como você deve estar percebendo, sou filha de pai preto e mãe branca. A Lélia nunca escondeu esse amor por esse homem, e assume esse sobrenome com muita lucidez do que ela está fazendo, ela fala isso. Sempre me chamou muita atenção. Às vezes, algumas companheiras escondem os maridos, namorados brancos, e a Lélia nunca escondeu esse homem, né? A Lélia sempre diz que ele foi um homem triste, mas que foi um homem, para ela, muito bom e importante em sua vida. Essa história me toca muito.

R. R.: Verdade.

A. C.: Eu quero te perguntar: como era Lélia de Almeida? Eu só conheço a Gonzalez. Ela tem uma ironia nos textos dela, né? Ela tem um palavreado muito peculiar dela, mesmo. Para mim, isso enriquece muito, lendo. Mas, eu queria saber isso: como ela era? Como era tua mãe?

R. R.: Bom, ela era uma pessoa mãezona, mesmo. Apesar de todo esse estigma que vocês conhecem da Lélia Gonzalez ativista, ela era mãezona. Tipo, para você ter noção, quando eu comecei, na adolescência - com uns 15, 16 anos, quando a gente começa a sair -... você vai numa festinha e tal, eu lembro que, toda vez que eu chegava em casa (a gente morava no Cosme Velho), ela saía do quarto. Ou ia beber água ou ia para o banheiro. E eu falei assim: "mãe, por que você só sente sede ou vontade ir ao banheiro quando eu chego?" [risos]. Mas era aquela coisa de mãe: "pô, que horas o meu filho está chegando?", “ele está chegando bem?”, sabe? Então, assim, é um lado que poucas pessoas têm conhecimento, né? Outra coisa, ela me chamava de "filhote". Eu me lembro de que, às vezes, na PUC [Pontifícia Universidade Católica], eu já casado, ela falava assim: "não, gente, hoje o meu filhote vem aqui, na sala de aula", e todo mundo imaginava um adolescente, e eu não sou um cara pequeno, eu tenho um metro e oitenta, sou grande. Aí, chegava um negão, de um metro e oitenta, na sala de aula, filhote de Lélia. Todo mundo pensando que eu era uma criança de 13, 14 anos. Tinha uma outra coisa, também, ela era extremamente carinhosa com os netos. Até eles lembraram, nessa live que você citou, que ela pedia, gostava, quando eu a levava na PUC, para apresentar os netos para os 
alunos. Ela era uma pessoa muito carinhosa, e a gente tinha uma relação muito estreita, né? Como de amigos, mesmo. Por exemplo, quando a gente se desentendia no sentido de opiniões, acho que era legal a gente conseguir debater. Eu me lembro de que, quando eu entrei na faculdade de Economia e comecei a estudar com mais profundidade Marx, a gente saía na porrada discutindo Marx, porque discordava. Mas, eram coisas de muita aprendizagem. E tem umas coisas que eram muito legais, sabe? Do tipo, as reuniões do MNU - que, na verdade, era o Movimento Negro Unificado contra a discriminação racial -, às vezes, ocorriam lá em casa. Então, tinha um monte de gente, Astrogildo, Lincon, Almilton, pessoal de São Paulo, a grana era curta, apertada, então ficava um na casa do outro, né? Você imagina... "Ah, vou para o Rio Grande do Sul, vou ficar na casa da Amanda, porque não tenho grana para pagar hotel". E o mais interessante é que o movimento das mulheres negras também ocorria lá em casa; algumas reuniões ocorriam lá em casa, então, eu tive a oportunidade de viver isso. Eu não fui um militante ativista, de participar de reuniões, porque eu não gosto disso. Eu acho que a minha militância - e isso ela nunca me cobrou... Porque a militância é o dia a dia, é quando você sai para trabalhar, quando você está dentro do ônibus, do metrô, quando você para no sinal, quando você entra no mercado, a militância, ela ocorre sempre, não é só em sala de reunião, onde a gente tem um pouquinho de noção do que é racismo e fica discutindo, é ver as coisas acontecendo na rua e sair na porrada, entendeu? Ela tinha essa visão, e eu tive essa oportunidade de ter essa convivência, de conhecer pessoas. E, o que é mais importante: na minha época, quando eu fiz o curso de datilografia, eu era um bom datilógrafo. Em geral, os textos dos manifestos e os textos dela, quem datilografava era eu. Então, eu tinha a oportunidade de conversar, de a ouvir falar, e mentalizava quando eu começava a "bater", porque, como eu era um bom datilógrafo, eu não olhava para o papel ou para a máquina. Nisso, eu memorizava. O livro Lugar de negro, que ela fez com Hasenbalg ${ }^{1}$, eu bati ele todo, entendeu? Ela escrevia os textos dela e passava para eu datilografar. Às vezes, eu passava a noite lá, ela escrevendo e eu datilografando. Isso me deu uma oportunidade de conhecimento não só na convivência, mas de poder fazer essas coisas, muito legal! Tinha uma coisa interessante, que vocês não veem hoje - você é mais nova do que eu -, que era a notícia ser muito demorada. Eu lembro que, aos domingos, quando acordava, eu ia à padaria, comprava um pão, presunto, um queijo, fazia um café da manhã diferente. Nós éramos assinantes do Jornal do Brasil. Ficava acumulado o jornal da semana inteira, e a gente ficava lendo para se atualizar [risos]. Então, você lia o jornal de segunda, de terça... para saber o que acon- 
teceu durante a semana, e falava "pronto, estou informado, então, está tudo bem”. Hoje, não, você leu aqui, daqui a meia hora já não é mais, já está obsoleto, né? Era assim, são passagens muito interessantes. É... Quando eu levava as crianças na casa dela - na época, ela já morava em Santa Tereza; logo que me casei, ela foi morar em Santa Tereza -, então, me obrigava a levar as crianças para passear de bonde. Aí, as crianças lembram que Lélia conversava, dava folha para elas escreverem, contarem histórias. Era uma pessoa muito terna, muito amorosa. Inclusive com as filhas das minhas primas, enfim, na intimidade, ela era muito carinhosa. Você vê, nos discursos dela, ela pedir desculpas, porque ela dava porrada em todo mundo, mas, na intimidade, ela não era assim, ela era muito carinhosa. Uma coisa que sempre me chamou atenção na minha mãe é que ela sempre - e isso eu aprendi com ela - mantinha um sorriso no rosto. Ela estava sempre rindo, até nos momentos difíceis. Pouquíssimas vezes eu vi minha mãe chorando na minha vida! Quando ela faleceu, em 94, eu estava com 33 anos, e eu nunca a vi chorando, pouquíssimas vezes. Isso é de uma força muito grande! Não é aquela coisa de “ah, chorar...”. É de ela conseguir segurar a onda, segurar a barra. Para mim, é muito legal!

\section{A. C.: Rubens, a casa onde ela faleceu... ela faleceu em casa, né? Essa casa segue sendo da família? E os pertences dela?}

R. R.: Não, não. O que acontece, os pertences, a gente... Porque, na época em que ela faleceu, a Lili morava com ela. Eu estava casado. Em 1992, eu me separei. E, com essa separação - acho que nada acontece à toa na vida da gente -, ela falou: "vem morar comigo! Se você está separado, volta para casa!". Foi quando eu cheguei lá e levei um susto, ela estava super magra. Eu falei: "vamos ao médico". Foi quando, em 1992, descobrimos a diabetes dela. Aí, durante esse período, eu morando com ela, nós fizemos o tratamento e tal, ela estava muito, muito magra. Aí começou, quer dizer, se recuperou. Só que a diabetes deixa sequelas, e uma das sequelas foi o coração. Eu acho que já havia feito o que tinha de fazer; comecei a me acertar com a minha mulher e voltei para casa, e a Lili foi morar com ela, entendeu? Assim, eu acho que eu me separei para ir lá cuidar dela, coisas que, assim, não têm outra explicação. A Lili estava morando com ela, quando ela faleceu. De coisas pessoais, roupas, enfim, quase não tem. Mas, algumas peças de bijuteria, joias... E ela tinha muitos livros. Está tudo no acervo dela. A gente está fazendo contato com uma grande instituição, para doarmos este acervo para eles digitalizarem - toda a obra dela, tudo o que ela escreveu - e deixarem isso público. O acervo, se você quiser acessar... Uma instituição extremamente respeitada, grande, para fazer isso. 
Fora isso, vai ter também muitas das coisas pessoais dela no Instituto Memorial, entendeu? Esse acervo que a gente está criando, deu um problema. $\mathrm{O}$ dirigente faleceu no ano passado, e há alguns rituais que devem ser cumpridos depois do desencarne: você tem que esperar no mínimo nove meses, um ano, para poder mexer nas coisas; não é: "ah, vou lá, abrir o armário e tirar uma calça para eu vestir”, a coisa não se dá dessa forma. Mas isso tudo está sendo encaminhado por nós. Logo, vocês vão saber da coisa toda. Só não aconteceu ainda por conta da pandemia.

\section{A. C.: Rubens, qual é o principal legado que a Lélia Gonzalez, ou para ti, né, tua mãe, Lélia de Almeida, deixa para nós?}

R. R.: Olha, uma das coisas que eu acho que é fascinante na vida dela é a Lélia Guerreira. Ela era uma guerreira, não desistia. Levou muita porrada, de todas as formas, de gente do movimento negro, do movimento feminista, de gente da academia, que ela prezou tanto, mas ela não desistia, e isso é um grande legado que eu tenho dela, e que ela deixou para mim, que é o de ser guerreira. Tudo é possível! Focando, mentalizando, lutando, a gente consegue as coisas que precisam ser conquistadas. Uma coisa que eu sempre aprendi com ela, e que eu sempre uso, é: “Nunca perca seus sonhos de vista!". Uma frase que ela me disse algumas vezes, e eu repito para várias pessoas, mais amigas, mais íntimas, né? Eu repito isso: não perca seus sonhos de vista!

\section{A. C.: E, de tudo o que você datilografou da grande intelectual Lélia Gonza- lez, qual é a principal obra, a de que você mais gosta?}

R. R.: Ah! Foi muita coisa, muito manifesto, o livro Lugar de Negro. Eu não consigo denominar ou nomear o mais importante. Para mim, todos foram importantes. Acho que tudo o que ela fez foi muito importante, tudo o que ela produziu, o pensamento dela, foi muito importante. Só posso dizer o grande privilégio que eu tive de fazer parte disso. Nem é no sentido de vivência, mas, datilografando. Então, não consigo te dizer: “ah, aquele texto...”, “ah, aquele pensamento.”. Não, não, eu não consigo pensar um que tenha sido mais legal ou menos legal. A gente acabava discutindo, conversando, falando: "ó para isso, para aquilo, e tal... é assim, assim, assado”. Não dá para nomear, Amanda, o A, o B ou o C. Todos foram importantes, até pelo significado que isso tem hoje. Porque, assim, na época... Você imagina, eu com 18, 19 anos, datilografando as coisas da minha mãe, que eu aprendi, mas ninguém, nem a gente e nem ela, tinha a noção da proporção que isso tomaria? A gente não tem bola 
de cristal para falar: “ah, isso aqui eu vou guardar, vou fazer”. Não. Algumas coisas devem ter se perdido, mas, ela era muito organizada, você está entendendo? A gente nem imaginava que várias coisas fossem acontecer, enfim... Tem umas coisas que eu acho bem legais. Por exemplo, uma coisa que me chamou muita atenção: a maior parte da vida profissional dela, na academia, foi dentro da PUC, né? Apesar de ter dado aula na Federal como convidada, na UERJ [Universidade do Estado do Rio de Janeiro]. Era uma coisa que me chamava muito a atenção na PUC. Quando a gente fala em ações afirmativas, você pega, no final dos anos 80 , ela andando pelo pátio, pelos pilotis da PUC... ela abordava um preto ou uma preta que ela sabia que eram bolsistas. Você imagina: dentro da PUC do Rio de Janeiro, onde está a elite carioca - a nata branca carioca estuda lá -, ela perguntava se a pessoa estava se alimentando, se a pessoa tinha e estava conseguindo comprar os livros, se a pessoa estava conseguindo se locomover de casa para a faculdade, e da faculdade para casa. Então, era uma coisa que não é porque: “ah, você é filho dela”. Não, isso é muito emocionante, partindo de uma mulher, sabe? Estou te falando, ela estava falando de ação afirmativa nos anos 80 ! Quem é que tinha esse pensamento e essa preocupação de dar oportunidade, de pensar em pessoas negras na universidade? Olha a cabeça dessa mulher! O que se passava na cabeça dela? O que ela queria da vida? O que ela queria para o povo dela, sabe? Isso, para mim, é fabuloso!

\section{A. C.: É emocionante mesmo! E uma última pergunta. Rubens: há um livro da Lélia que eu nunca consegui comprar, que é Festas Populares. E aí, no ano passado, surgiram informações de que a Boitempo lançaria as duas obras, tanto Lugar de Negro como Festas Populares. É, verdade isso? Você pode nos falar a respeito?}

R. R.: Claro que sim! A Boitempo vai reeditar o Festas Populares. O que acontece: essa coisa da pandemia mexeu muito com a estrutura do Brasil. Quer dizer, não somente do Brasil, mas do mundo. Então, alguns projetos que já eram para estar na rua, falando de um modo geral, não aconteceram por conta da pandemia. Então, de fato, a Boitempo vai reeditar o livro Festas Populares e a Zahar, que é a Companhia das Letras, vai reeditar Lugar de Negro; a que lançou Por um feminismo afro-latino-americano vai reeditar esse. A gente só está aguardando o cenário empretecer - porque negócio de claro, para mim, não dá, a gente fala que vai ficar preto, que é onde você consegue enxergar as coisas [risos]. Quando a gente vir um cenário melhor, porque não há certeza, hoje, de que caminho se tomar, né? E como, dentro da minha profissão, dentro 
da minha formação, eu vejo coisas muito ruins daqui para frente, por tudo que tem sido feito por esse Paulo Guedes - mas, enfim, não vou fazer juízos de valor quanto a isso... Então, até que essas coisas... Por exemplo, houve o lançamento do Por um feminismo afro-latino-americano. Foi muito legal. A FLUP (Feira Literária das Periferias) queria fazer uma homenagem, e aí foi uma coisa virtual, porque até aquela coisa de lançamento de livro se faz organizando uma noite de autógrafos... Pô, não dá para fazer, né, Amanda? Como é que você vai aglomerar pessoas, entendeu? Então, ele pegou um bonde legal. Ainda não surgiu uma oportunidade dessas para esses outros, então, tem que esperar as coisas se acalmarem e saber qual o rumo tomar, mas vão sair, sim. Os contratos estão assinados, já têm autorização, a gente só está esperando que as coisas tomem um rumo, se normalizem, para poder divulgar. Só não é verdade que Lugar de Negro sairá pela Boitempo. Ele vai ser publicado pela Companhia das Letras.

\section{REFERÊNCIAS}

GONZALEZ, Lélia; HASENBALG, Carlos. Lugar de Negro. Rio de Janeiro: Marco Zero, 1982.

GONZALEZ, Lélia. Primavera para as rosas negras: Lélia González em primeira pessoa. São Paulo: Editora Filhos da África, 2018.

GONZALEZ, Lélia. Festas Populares no Brasil. São Paulo: Editora Index, 1987.

RIOS, Flavia; RATTS, Alex. Lélia Gonzalez - retratos do Brasil negro. São Paulo Editora Selo Negro, 2010.

RIOS, Flavia; LIMA, Marcia (Orgs.). Por um feminismo afro-latino-americano - Lélia Gonzalez. Rio de Janeiro: Editora Zahar, 2020.

NOTA

${ }^{1}$ Sociólogo argentino que atuou como professor e pesquisador nas áreas de relações raciais, estratificação social e mobilidade social. 